\title{
XXX. Description of the mooring blocks now used in Portsmouth harbour
}

\author{
Mr. J. Park
}

To cite this article: Mr. J. Park (1820) XXX. Description of the mooring blocks now used in Portsmouth harbour , Philosophical Magazine Series 1, 56:269, 188-195, DOI: 10.1080/14786442008652391

To link to this article: http://dx.doi.org/10.1080/14786442008652391

冓 Published online: 27 Jul 2009.

Submit your article to this journal $\sqsubset x$

Џ Article views: 2

Q View related articles $\asymp$ 
as other eye-tubes, and is adjusted to distinct vision by the same pinion motion.

For the lowest magnifying power, the whole of the tubes must be shut up; and when the magnifying power is to be increased, the smallest of the sliding tubes, A, must be drawn out to either of the numbers engraved upon it; care being taken not to draw out any part of the other sliding tubes, $B$ and $C$, until the whole of the first, $A$, is pulled out; the second tube, $B$, may then be drawn out to either of the numbers engraved thereon; and in like manner the third tube. The numbers denote the magnifying power of the telescope.

To change the power, for any less power than the one to which the tubes have been drawn out, the reverse of the above described mode of proceeding must be observed; and the largest tube must be returned first, and so on, until they have been brought back to the number required. Each alteration of the magnifying power will require a new adjustment of the pinion; and as the magnifying power is increased, the distance between the eye-glass and the object-glass must be diminished.

* * It is applicable to achromatic and Newtonian telescopes of all lengths.

XXX. Description of the Mooring Blocks now used in Portsmouth Harlour. By Mr. J. РАRK of Portsmouth*.

Gentlemen,-I TRUst that the communication which I am about to lay before you will not be deemed altogether undeserving your notice.

In October 1795 I was appointed junior master attendant of Portsmouth yard; and as the security of his majesty's ships and all works on float relative thereto are in the master atterdant's department exclusively, I applied myself as much as possible to gain a thorough knowledge of the harbour, as well as of the nature of the security and disposition of the moorings; and the more I became acquainted therewith, the less satisfied I was with the method by which the ground-chain was secured, as a national evil attended it, and various other inconveniences to the public service.

The evil alluded to was that of throwing some thousand tons

* From the Transactions of the Society for the Encouragement of Arts, Manufactures, and Commerce, vol. xxxvi. The gold medal of the Society was presented to Mr. Park for this great improvement respecting harbours for king's ships; and a model of the contrivance is preserved in the Socicty's Repository. 
of shingle ballast annually on what is called the claus of the moorings to render them secure, which ballast was by the wash of the tide carried into the bed of the harbour and lakes where the ships ride.

Having arrived at the head of my department in April 1812, 1 ventured humbly to recommend to the honourable Navy Board considerable alterations in the arrangement of the moorings, which would not only tend to improve the harbour by giving more space in the lower part, where the same was required for ships to pass and repass, but also afford accommodation to a greater number of them than hitherto could be laid up : the recommendation being favourably received, I was directed to proceed accordingly.

These alterations were effected; but the great and growing evil of filling up with ballast a harbour already too shallow, still continued, and produced an anxious wish for some substitute for the claw, by which the application of shingle ballast might be discontinued. I was accordingly induced to make several experiments, and after various trials, I submitted to the Navy Board a model of a cast-iron Mooring Block which appeared to promise fair to do away every objection arising from the method of securing the ground chain, being at once a substitute both for claws and mooring anchors.

The Board directed two to be cast of such form and weight as I wished, and when received in the yard, trials to be made to ascertain what degree of resistance they possessed.

When received, trials were made under the inspection of several experienced and distinguished naval officers, and the prin-cipal officers of the dock-yard; which proving satisfactory, induced me to address the Navy Board on the 2 nd of November 1814, detailing my sentiments, \&c. relative to Portsmouth harbour, and the moorings, accompanied by accurate statements of the trials made with the blocks, copies of which I have annexed hereto, having first obtained the Board's permission to do so.

A trial being ordered on a lighter block, and proving equally satisfactory, directions were shortly after given for their general adoption, to the exelusion of every thing hitherto used for securing moorings, and a contract immediately entered into for the supply of them.

The superiority of the block in question over both claws and anchors is manifest ; it will last for ages without repair, will resist much greater power than either, and will completely obviate the use of shingle ballast to render the mooring secure, (which must hitherto have been extremely injurious to the harbour, as 
on applying a strain it has a tendency, arising from its form, to bury itself more and more under the surface until it becomes fixed ; it is likewise free from liability to be hooked by ships' anchors, and the moorings thereby rendered insecure; which has been the case hitherto, as represented in my letter to the Board above quoted.

I now beg leave to notice the Mooring Blocks in an economical point of view.

The largest blocks, adapted for first-rates' moorings, are now supplied for less than half the sum required to provide and fix what is termed a claw, and about a quarter of the cost of a mooring anchor.

It must also be considered that both the anchor and claw would require to be replaced in the course of forty or fifty years, (supposing them to remain undisturbed,) besides which the claw would require frequent repair from the effect of the worm during that period.

On the blocks already laid down at this port (although principally as substitutes for claws) there arises a saving to the public of upwards of $3,000 l$. ; and where it may be necessary to lay them down instead of auchors, the saving will be infunitely greater.

It may not be amiss to mention, that an opinion prevailed that the block invented by me was only an improvement on one invented by Mr. Hemmans of Chatham Dock-yard some years ago ; but on an examination of the two by a Committee of the Navy Board, the same was clearly proved to be erroneous: the Report to the Admiralty on that subject, and recommending the general adoption of my block, was as follows, viz.:

"The Committee has further to remark, that Mr. Park's Block cannot be considered as an improvement on the plan of Mr. Hemmans, being totally dissimilar; but altogether as a new invention, and having the same object in view."

As a model and drawing of the block are forwarded, I decline giving any written description of it here; but should the Society require further particulars, I shall have much pleasure in furnishing them.

I have only now to observe, that having been influenced by a strong sense of public duty, and an ardent desire to be useful to my country by overcoming the serious evils set forth in my narrative, I trust it will not be considered too presuming to request as a mark of your approbation that you will be pleased to give my invention publicity.

A. Aikin, Esq. I am, Gentlemen, \&c. Secretary, \&ै. J. PARK. 


\section{Copy of a Letter addressed to the Hon. the Navy Board.}

Portsroouth-yard, Nov. 2, 2814.

Honourarle sirs, - Having from my first appointment to Portsmouth-yard as junior master attendant, dedicated as much time and attention as in my power towards acquiring a thorough knowledge of the harbourr, both as to the depth of water and quality of the ground, and also to the method of preparing and laying down moorings, together with any improvements that might be made, either for their security or for increasing their numbers by a more advantageons arrangement, or by laying down additional ones where found practicable:

I have in the course of my practice (which has been now upwards of 19 years) experienced many inconveniences, which I have long conceived might be removed by making some alteration in the manner, of securing the ground-chain.

I have likewise been of opinion from an early period after my appointment, that many advantageous alterations might be made among the moorings in various parts of the harbour, as well as that new moorings might be laid down both for ships of the line and frigates in the different lakes; and having submitted the same to your Honomable Boarl by letters of the 30th April 1812, and 26 th July 1814, was directed by your warrants of the 8th May 1812 , and 28 th July 1814 , to carry the propositions into effect: in consequence of which, several alterations have been made, and many new moorings laid down, and much may yet be done when the other duties of the port will admit : but as I am preparing a plan of the harbour, which will show the alterations, \&c. much plainer than any written description, I shall decline saying more at present, and endeavour to describe the manner of securing the ground-chain, with the inconveniences alluded to.

The ground-chain of all the swinging moorings in the harbour is secured as follows :

One end is fixed to what is termed a claw, namely, a frame of wood, with an iron ring in the front for shackling the chain to, which claw is buried below the surface from 2 to 3 feet, by digging away the mud or ground as near the low water mark at spring tides as circumstances will admit, with piles driven in the front, and when completed, the mud which has been removed is thrown on the claw so as to cover it.

The other end of the chain is secured by a mooring anchor, nainely, two anchors of about $70 \mathrm{crvt}$. each, in one stock, with their upper hooks either taken off or beaten down on the shank; this is for line-of-battle ships' moorings; frigates' moorings have only one anchor of about $60 \mathrm{cwt}$.

From this harbour having for some years become a rendezvous for ships in the transport service, and thereby crowded with ships 
of that description, together with the liability of the mooring anchors, from their construction, to be hooked by the transports' anchors, much inconvenience, labour and risk have been experienced, and many instances have occurred when it has been necessary to take up a mooring from end to end; in consequence of ships having hooked the mooring anchor, and, regardless of every thing but the recovery of their own anchors, have hove down unobserved in the night-time at low-water, and by the rise of tide forced the mooring anchor out of the ground; nor did I ever find one so displaced, when taken up, entire; but, on the contrary, one anchor has been lying across the other, the stock broken or gone, or the chain foul of the flooks, and I have seen instances when the mooring anchors have been completelv upset and found with the flooks, uppermost. Having described the swinging moorings, and also what I humbly consider objections to the anchors, and the principal inconveniences arising therefrom (I say principal, because there are others, particularly where the anchors lie in shoal water, the frequency of their being injured by ships grounding on them, $8 \mathrm{c}$.), I have now to state that all the head and stern moorings in the different lakes are secured by claws only, the chain being laid from shore to shore, and each end shackled to a claw : this method of securing the chain is not however, in my opinion, without objections, and to which I humbly call the attention of the Board.

Notwithstanding the claws are perfectly buried when laid down, yet in the course of twelve months they appear-above ground, and frequently require a supply of shingle ballast to be thrown on them, particularly in the lakes where the stream is narrow; and as the disappearance of this ballast can only be accounted for, by its'being washed down by the tide into the bed of the harbour and lakes, I cannot divest myself of the opinion that the same must prove detrimental to the harbour.

These considerations juduced me to search for a substitute, free from sụch objections, to answer the purpose either of the claw or the anchor; and after making various trials I submitted for the inspection of the Committee of your Honourable Board, who visited Portsmouth in September 1813, the nodel of a castiron block; when they were pleased to give directions for two being provided ; and your Honourable Board have also directed, by warrant of the 6th July last, the two blocks to be received and tried : they have accordingly been received, and trials made with every possible power, applied to ascertain their stability; and as every one who has witnessed the experiments is fully conrinced of the superiority of the blocks, I trust I shall not be considered too presuming in recommending their adoption for claws as well as anchors, as I am given to understand the cost will not much 
much exceed the expense of making and fixing a claw, which is liable to injury, by vessels grounding on, or hooking fast to it, nor is its durability beyond 40 or 50 years, even where it remains undisturbed, whereas the cast-iron blocks will last for many centuries.

I am likewise informed that the blocks may be cast at the foundry, in the yard, if your Honourable Board should approve of a furnace being erectcd for that purpose, which would materially lessen the expense.

I have hereunto annexed a description of the trials, and have forwarded by this night's coach, two drawings. chain.

No. 1 , showing the present method of securing the ground No. tried.

And by Clark's waggon, a model of the block.

$$
\text { I am, sir, \&c. }
$$

\section{J. PARK.}

Description of the Trials made with the Cast Iron Mooring Block, inviented ly me, and now humbly sulmitted for the consideration of the Honouralle Navy Board.

First, The cast-iron mooring block, weighing 142 civt. was placed on the shore some distance from low water mark, and an anchor of $85 \mathrm{cwt}$. (exclusire of the stock, which weighed about $35 \mathrm{cwt}$.) was also placed the same distance from low water mark, and 65 fathoms from each other, on ground of the same quality; 15 fathoms of mooring chain were attached to each, and to the end of each chain four treble blocks of 22 inches; four threefold purehases of new 6-inch hawser rove, and two mooring lighters, with 40 men in each, grounded, one abreast of the castiron block, and the other abreast of the anchor ; the falls were brought to the capstans and windlasses and the strain applied to heave the mooring hock and anchor towards each other.

Both drew; the former one inch to one foot of the latter, until the mooring block had drawn about the distance of its own base, when having completely buried itself, it became stationary, but the anchor continued to come home (notwithstanding it was buried to the upper flook) until every one present was satisfied that any further trial with an anchor of that weight was useless.

Second, being willing to make further trial, I caused an anchor of 95 cwt. (namely, the Nelson's best bower) to be laid down as before, and the same purchase to be applied; but the power not being sufficient to move either the block or anchor, $10 \mathrm{ad}-$ ditional men were sent into each lighter, when the anchor started,

Vol. 56. No. 269. Sept. 1820.

$\mathrm{B} \mathrm{b}$

and 
and continued drawing, notwithstanding it soon buried itself (as the former had done), but the block remained immoveable.

Although this trial was very satisfactory, yet wishing to ascertain the power of resistance which the block possessed, I caused the following one to be made.

Third, an anchor of $41 \mathrm{cwt}$. was laid down about 60 feet behind the large anchor, and attached to it by cable, and on applying the same purchase as above, the large anchor drew until the cable between the anchors became taught, when it was found necessary to increase the power, which being done, both anchors started, and continued to come home, until the superiority of the mooring block (which still remained frm) was declared to be so manifest, that no further experiment was necessary, it being the opinion of the gentlemen under whose inspection this last trial was made, viz. Admiral Sir Richard Bickerton, bart.; Rear Admiral Foote ; Commissioner the Hon. Sir George Grey, bart.; Captain Sir James Athol, Wood Hewitt, and the principal officers of the Dock-yard;-that it was much superior to any thing yet offered for the purpose of securing the ground chain of the moorings, and that its introduction would prove advantageous to the service, particularly in shoal water where ships had to pass over the auchors.

J. PARK.

\section{Statement of Trials made with a lighter Cast-Iron Mooring Block.}

First, the mooring block weighing 115 ewt. was placed on the shore near low-water mark, and also an anchor of 95 cwt. (exclusive of the stock) about 65 fathoms from each other, with 15 fathoms of mooring chain attached to each, and to the end of each chain four treble blocks of 22 inches, four three-fold purchases of new 6-inch hawser rove, and two mooring lighters, with 50 men in each grounded, one abreast of the mooring block, and the other abreast of the anchor; the falls were brought to the capstans and windlasses, and the strain applied to heave the mooring block and anchor towards each other (similar to the trials made with the former block, a statement of which accompanied my letter of the 2nd of November last).

The block and the anchor both drew about the distance of seven feet, when the block became fixed, but the anchor continued to draw as long as the purchase was applied.

Second, an anchor of $43 \mathrm{cwt}$. was laid down about 10 fathoms behind the large anchor, and attached to it by cables (termed by seamen, "backing an anchor") when the purchase was again applied by $64 \cdot \mathrm{men}$ - in each lighter: the large anchor drew, taking the small one with it, until the latter had buried itself up to the crown, when the anchors became stationary, and the block 
began to draw, and continued to do so while the strain was applied.

Third, having removed the anchor of $43 \mathrm{cwt}$. and laid down one of 23 cwt. instead, at the distance of 15 fathoms behind the large anchor, the same purchase was again applied, when both anchors came home.

The block, after having drawn about seven or eight inches, became fixed, but the anchors had drawn 13 feet, and kept coming home as long as the purchase was continued, and until it was evident that the block was superior to the anchors.

'The foregoing trials were made under the inspection of $\mathrm{Ad}$ miral Sir Edward Thornbrough, K.C.B.; Rear Admiral Halkett, Commissioner the Hon. Sir George Grey, bart.; Captain Hewitt; the Master Shipwright, Master Attendant, Engineer and Mechanist, \&c.

J. PARK.

\section{Reference to the Engraving of Mr. J. PARK's Cast-Iron Mooring Block, Plate II.}

AAAA, the extent of the lower flat of the block.

$B B B B$, the extent of the upper flat.

$\mathrm{C} \mathrm{C}$, for lowering the block into its place.

$D$, the neck of the block, to which the chain is attached.

$\mathrm{E}$, the shackle which connects the mooring chain to the block.

Side View.-F G gives the block an inclination to dive into the ground when strain is applied.

XXXI. Electricity and Galvanism explained on the mechanical Theory of Matler and Motion. By Sir Richard Phullips.

$I_{s}$

$\mathrm{v}$ no branch of philosophy have superstition and the love of the marvellous revelled in greater luxury of variety and absurdity, than in every existing disquisition, observation, and theory of the classes of phænomena called Electrical.

Theories assuming miraculous principles which never had existence, and which are inconsistent with that supreme power for whose support they were weakly invented, and then a course of reasoning by false analogies, have led to all these absurdities. The philosophical electrician talks flippantly of his fluids and his fires-his negatives and his positives-his charges, surcharges, and discharges-his saturations and non-saturations-his attractions and repulsions-and other conjurations-and believes that he can bottle up this flujd sui generis; that a clond can be surcharged with it ; that bodies contain more or less than their natural quantity; and a hundred other equal errors. It is therefore to be feared, that he will be as much enraged at the writer 
Fig.71.



D

B



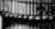

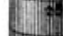

$-4$



$\frac{-12}{200}$

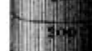

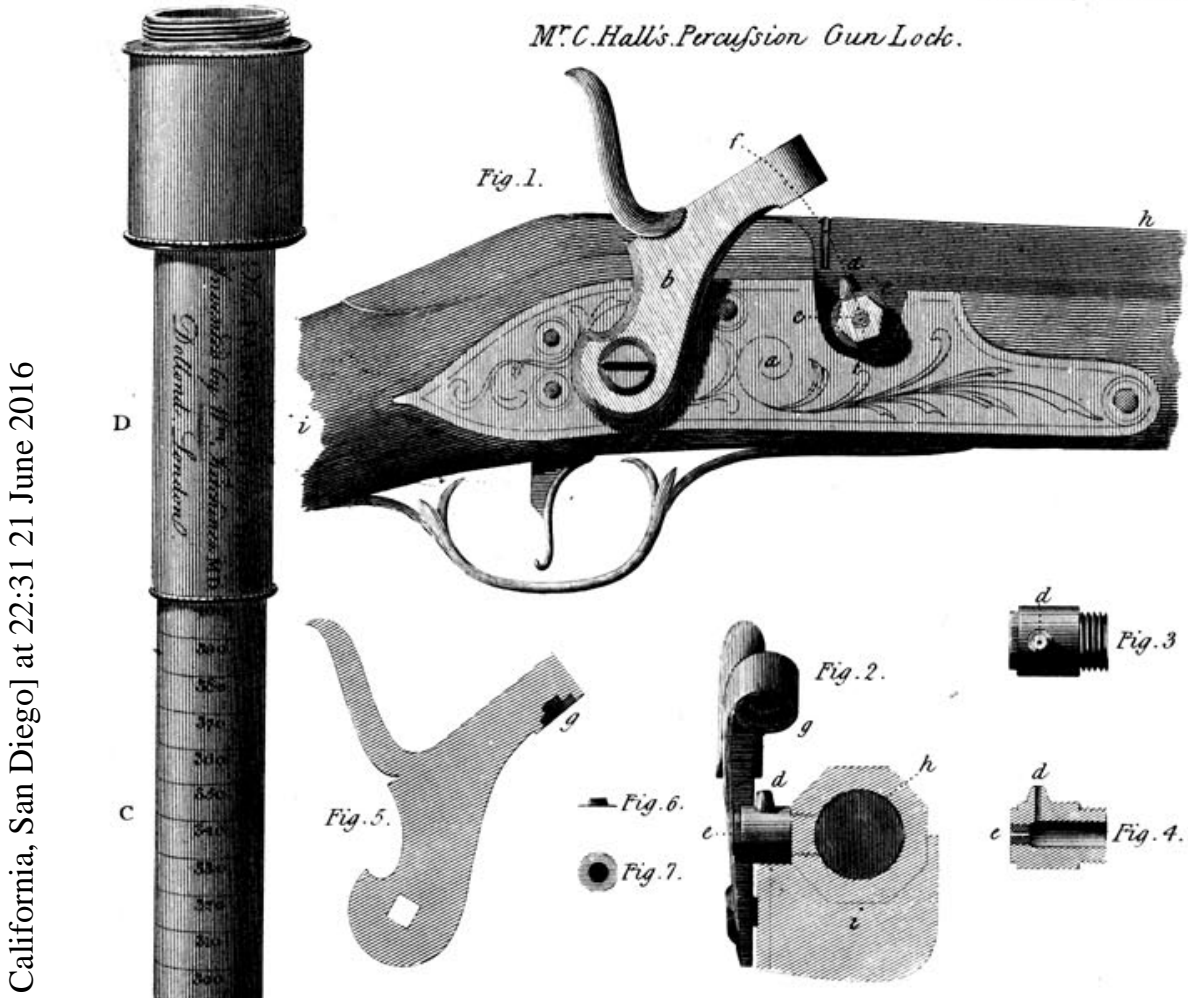

$=$ Fig. 6 .

Fig. 7.
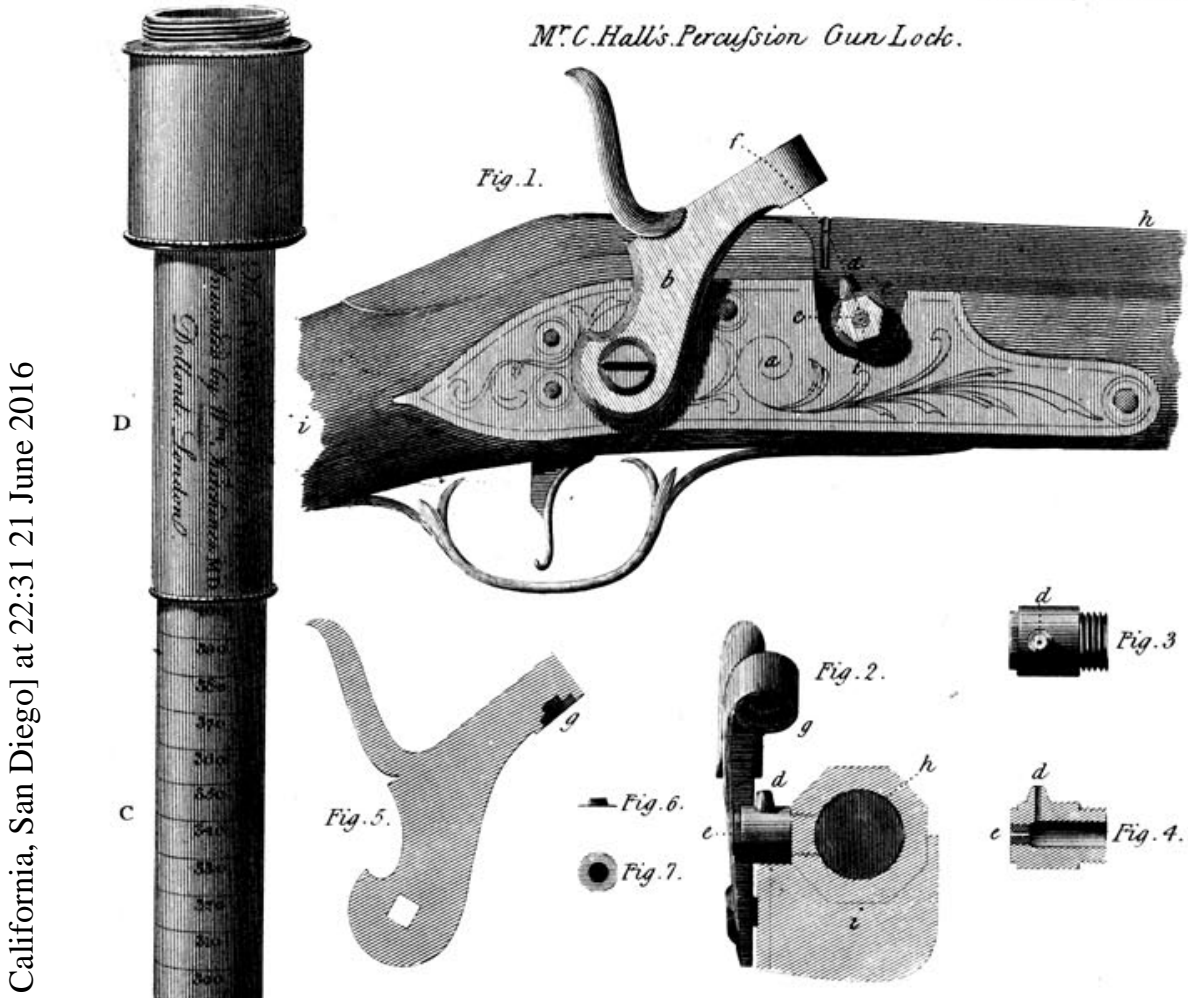

MrJ.Parkis Cast Iron Mooring Block .
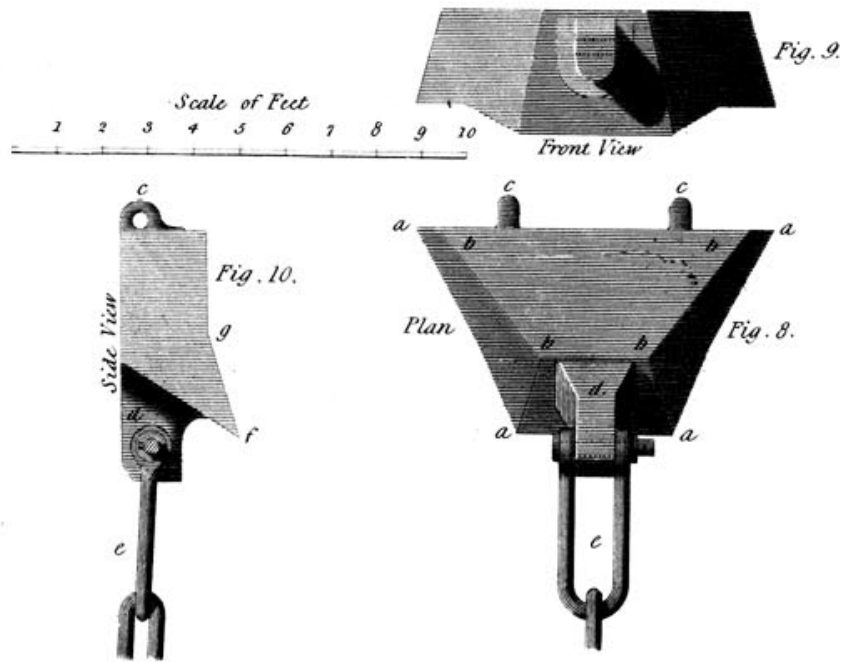

$\frac{200}{1900}$
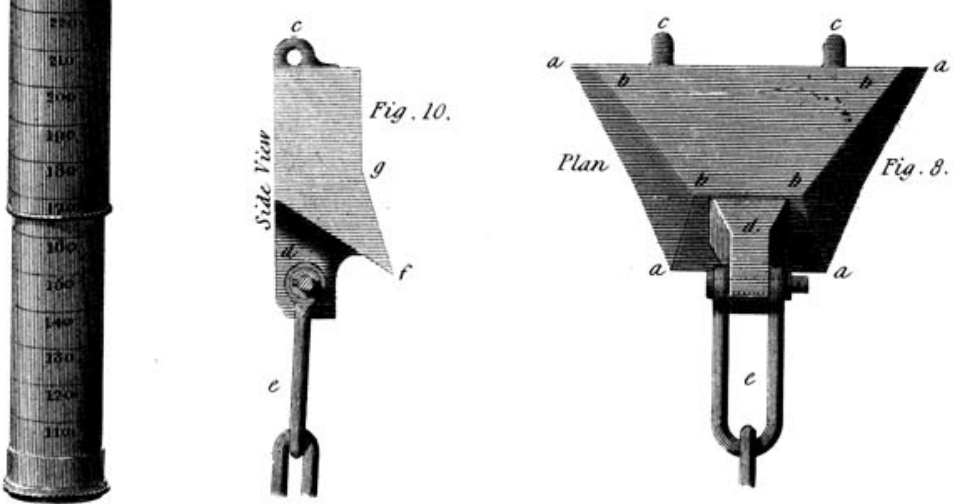